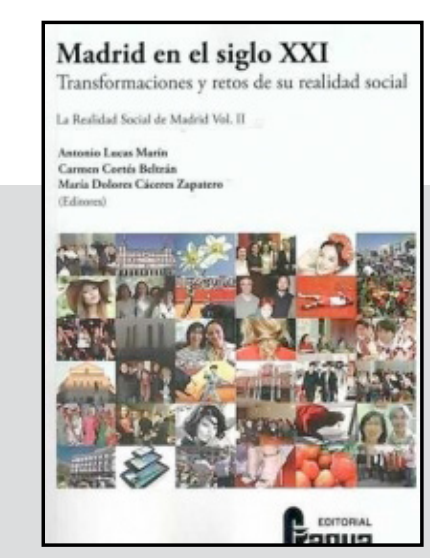

Madrid en el siglo XXI. Transformaciones y retos de su realidad social. La Realidad Social de Madrid Vol. II Antonio Lucas Marín Carmen Cortés Beltrán María Dolores Cáceres Zapatero Editorial Fragua, Madrid 2013

\title{
Madrid en el siglo XXI. Transformaciones y retos de su realidad social
}

\begin{abstract}
Ts el título elegido por la Asociación Madrileña de Sociología (AMS) para el segundo volumen de lo que pretende ser una trilogía sobre la Realidad Social de Madrid. Tras el éxito del trabajo realizado con el primer volumen, Antonio Lucas Marín, Carmen Cortés Beltrán y Dolores Cáceres Zapatero, vuelven a coordinar un proyecto excelente donde se da un paso más al esfuerzo comenzado con la edición anterior por dar a conocer aspectos nuevos de la estructura social del Madrid del siglo XXI, aportando enfoques y matices que quedaron sin analizar entonces.
\end{abstract}

En esta ocasión el libro consta de 519 páginas, articuladas en tres grandes apartados: un primer bloque centrado en las personas y el territorio; un segundo bloque que recoge aspectos sociales y económicos básicos o institucionales y una tercera, algo más ligera pero no por ello menos definitoria, de lo que es Madrid. Como ya pasara con el primer trabajo, estamos ante una obra coral, donde se han observado los fenómenos que constituyen el objeto de estudio desde la perspectiva histórica, la espacial y la de la desigualdad. 
La primera parte, titulada Las personas y el territorio comienza con el capítulo "Evolución demográfica y características poblacionales", escrito por Carmen Cortés Beltrán. Un análisis comparado de la evolución de la población de Madrid con respecto a la del resto de España, y de los movimientos naturales y migratorios madrileños. Entre las principales conclusiones que señala la autora, destacar que Madrid ha sido una de las comunidades autónomas con mayor desarrollo demográfico en los últimos cien años, en parte por el crecimiento económico espectacular que protagonizó en la década de los 60 . La población madrileña se establece en torno a tres zonas que dividen la Región: la corona metropolitana, los municipios rurales y la capital, habiendo ganado peso la primera con respecto a las otras tres.

Estamos ante una población longeva en comparación con el resto del país, con una natalidad superior y una mortalidad inferior a la de otras partes de España. Y es que Madrid ha vivido un momento donde los nacimientos eran muy escasos, y que se equilibró gracias a la población inmigrante, que ha sufrido una evolución espectacular en las últimas décadas, solo comparable con Cataluña, aunque superior a la experimentada allí. Movimientos que empiezan a variar su intensidad, debido a la crisis económica, y que presentan un fenómeno nuevo: la salida de madrileños hacia otros lugares de España y también al extranjero.

“Infancia y Adolescencia” es el título del segundo capítulo del libro, escrito esta vez por Lourdes Gaitán, Armando Bello, Olivia de Cos y Justina de Pablo. Un análisis pormenorizado de estos grupos de edad, donde se evalúan, entre otros aspectos, las condiciones de salud y la baja mortalidad en este segmento; su presencia en el sistema educativo (desde la inversión en educación hasta la evaluación de los resultados obtenidos en la misma); la pobreza infantil y las situaciones de riesgo de exclusión social; un análisis de las situaciones de desprotección dada la vulnerabilidad de la infancia y la participación social de los madrileños mas jóvenes, tanto en el ámbito escolar (Consejo Escolar, asociaciones de estudiantes, etc.), como en el ámbito local (gracias a las políticas culturales y de organización del tiempo libre). Un capítulo completo en el que se exponen de manera extraordinaria datos objetivos sobre la situación de los niños, niñas y adolescentes madrileños, que resulta especialmente interesante porque son escasos los estudios descriptivos que 
se encuentran sobre este tema, cuyo estudio parte con el hándicap de la falta de interés que suscita el conocimiento real de la infancia. Un asignatura pendiente, que justifica si cabe, trabajos como realizado por los autores en este libro.

"Dinámica territorial en la era de la movilidad" es el capítulo tercero. Escrito por Julio del Pino Artacho, quien toma como punto de partida la idea de que el territorio se construye a partir de las relaciones sociales que este soporta. A partir de esa idea, el autor analiza la dinámica de configuración interna de movilidad que ha experimentado la región. Las corrientes globales y las estrategias de ocupación han sido determinantes en los procesos territoriales de la Comunidad de Madrid, donde la capitalidad y la dominación funcional que tradicionalmente ha ejercido marca la pauta. De esta forma, son tres los espacios configurados (ya citados por Carmen Cortés Beltrán en el primer capítulo): la capital, el área metropolitana y la periferia. Del Pino explica cómo procesos como la inmigración internacional y la crisis iniciada en el 2008 han influido en la configuración del territorio y cómo en la primera década del siglo XXI son las tendencias recentralizadoras las que marcan las pautas, dejando un escenario cada vez más complejo.

Josune Aguinaga pone punto final a esta primera parte con el capítulo "El urbanismo madrileño. Del Casticismo a la Globalización". En él, la autora nos explica en qué contexto histórico se han construido las ciudades madrileñas, y enumera los principales planes de Ordenación Urbana que han afectado a su configuración y cómo la participación ciudadana ha estado presente en estos procesos. Desde los primeros asentamientos íberos, romanos y visigodos hasta el Madrid actual, como "smart city", modelo de la ciudad global en la que se ha convertido. Un capítulo lleno de ejemplos en un esfuerzo por explicar con la mayor exhaustividad posible, cómo Madrid ha llegado a ser lo que es y cómo la Sociología ha estado y está presente para explicar ese proceso. Pero no sólo eso, sino que estamos ante un texto con lugar para la crítica: a la inestabilidad de las leyes sobre territorio, el incumplimiento continuado de las mismas y la necesidad de nuevas teorías sobre sociología urbana que sepan adaptarse a las nuevas concepciones de ordenación de las ciudades, así como a las obras megalómanas y el trabajo de los profesionales a la hora de diseñar y conformar la ciudad. Aguinaga nos muestra en definitiva una ciudad dinámica con vida propia en la que

DOI: ri14.v12i1.686 | ISSN: 1697-8293 | Año 2014 Volumen 12 N 1 | ICONO14 
el objetivo ha de ser garantizar la calidad de vida, pelear por la transparencia y proteger la participación ciudadana.

Bajo el título "El Madrid institucional, económico y social", llegamos a la segunda parte del libro. Cuestiones nucleares como el marco político; la sanidad; la situación económica y las estrategias para enfrentarse a la crisis; los movimientos sociales y la siniestralidad laboral, entre otros, son tratados en los seis capítulos que la conforman. El primero de ellos, "Política, Gobierno y Administración", escrito por Rubén Tamboleo García, parte de un repaso histórico sobre la constitución de Madrid como Comunidad Autónoma. A partir de ahí, repasa desde un punto de vista descriptivo y crítico cómo es el Gobierno de Madrid, la Administración Pública (donde además analiza su evolución) y el sistema de partidos que configuran el panorama político de la región y la Asamblea de Madrid. Además evalúa el peso que implica para Madrid ser la capital del Reino y el papel que conlleva asumir esta posición en un modelo de descentralización del poder de España.

Continúa el libro con un texto de Juan Manuel García González y Laura Lorenzo Carrascosa, "La sanidad en perspectiva: debilidades, fortalezas y controversias". Un capítulo cuya lectura resulta fundamental para entender lo sucedido en los últimos meses con la Sanidad Madrileña, el intento de privatización del Gobierno (del que ya daban cuentas los autores en el momento de cerrar la edición, sin saberse aun el desenlace entonces) y la fuerza de la denominada Marea Blanca para evitarla. El lector encuentra en estas páginas una evaluación de la calidad de la sanidad y la percepción que de ella tienen los madrileños. Además se hace un pormenorizado análisis de los servicios sanitarios, la financiación de la sanidad y la gestión de los mismos; así como los recursos existentes y las políticas aplicadas, poniendo énfasis en la necesidad de transparencia de las políticas públicas que garanticen una asistencia sanitaria de calidad, basada en los principios de universalidad, equidad y solidaridad que contribuya a reforzar la cohesión social.

"Ascenso y caída de la economía madrileña: los efectos de la crisis económica", es el título del capítulo séptimo, a cargo de María Pilar López Portillo. La autora indica que los efectos de la crisis en Madrid han sido similares a los del resto de España, aunque la intensidad a nivel macroeconómico ha sido algo menor. El libro 
se publica cuando todavía era una opción abierta que el proyecto Eurovegas llegase a la Comunidad y aun no podían evaluarse las medidas adoptadas por la Reforma Laboral. Sin embargo, apenas un año después, se ha confirmado que el macrocentro de juegos no se establecerá en Madrid y que, por otra parte, los efectos de la reforma laboral no han sido los esperados. De hecho, los últimos datos publicados sobre el paro registrado en febrero de 2014, indican que mientras el paro ha experimentado una leve bajada en España, en la Comunidad de Madrid ha subido.

Antonio Lucas Martín escribe el octavo capítulo "Madrid, de villa a gran capital europea: inversión en I+D y uso de las TIC". Un texto donde el autor explica la transformación protagonizada por Madrid para adaptarse a la sociedad de información. Un proceso acompañado de una fuerte inversión en I+D que, sin embargo ha ido disminuyendo desde el comienzo de la crisis y que suponen un reto cuyas dificultades hay que intentar solventar para mantener y reforzar una posición competitiva en esta nueva sociedad.

El cambio de mentalidad que implica la llegada de las TIC ha llevado aparejado un proceso de transformación social hacia la modernización que en España ha estado encabezado por Madrid, País Vasco, Cataluña y Navarra, con un claro liderazgo de la capital en la consolidación de la nueva sociedad de información.

Ramón Adell Argilés escribe el capítulo noveno, titulado "La metamorfosis de los movimientos sociales (Madrid 1975-2013), donde tras una breve referencia a lo que son los movimientos sociales y cuál es su importancia, el autor repasa los principales movimientos que se han desarrollado en Madrid en las últimos 30 años y analiza los nuevos procesos participativos de "creatividad social" y la irrupción de los "indignados" de la Puerta del Sol.

Entre las principales aportaciones, destaca la idea de que los movimientos sociales en Madrid tienen una trayectoria consolidada, con ciclos de mayor o menor participación, fruto del cansancio y el auge de otras vías de participación. Desde la aparición de la crisis, los movimientos sociales han vivido un fuerte repunte al entrar en juego otra variable fundamental: el incremento de las desigualdades y el proceso de retroceso en las conquistas sociales del estados de bienestar, así como

DOI: ri14.v12i1.686 | ISSN: 1697-8293 | Año 2014 Volumen 12 N 1 | ICONO14 
la crisis de representatividad. Un estudio abierto que, como ya señalaba el autor, e incidimos ahora, resulta fundamental para evaluar la actualidad social madrileña y comprobar si todos estos movimientos descritos en el capítulo consiguen una capacidad de propuesta y se sitúan en posiciones de alternativa, como la aparición de determinados partidos políticos nuevos derivados de estos movimientos pretenden, o derivan en populismos.

Esta parte concluye con el trabajo de Pilar Nova Melle y Pablo López Calle de nombre "Repercusiones de la reorganización productiva en la salud laboral y la accidentalidad". Una continuación del capítulo escrito por los mismos autores en el Volumen I de esta trilogía sobre el mercado laboral y sus transformaciones, que en esta ocasión incide, tras repasar la evolución histórica de las transformaciones productivas en los últimos veinte años en Madrid, en las consecuencias de la precarización del mercado laboral, caracterizado por el infraempleo y la dualización. La altas cifras de siniestralidad (que aunque parecen que han disminuido, solo se han desplazado geográficamente a la vez que las actividades industriales hacia Toledo y Guadalajara, provincias limítrofes con la Comunidad de Madrid), las pésimas condiciones laborales y el incremento de las enfermedades profesionales, ofrecen la otra cara de la realidad del mercado de trabajo madrileño, que los autores complementan con el análisis de las normativas existentes y, especialmente, la Ley de Prevención de Riesgos Laborales.

La tercera parte, denominada "Aspectos enriquecedores de una realidad", resulta una amalgama de matices característicos de Madrid que resultan fundamentales para entender la realidad sociológica de la región. Comienza con dos capítulos de María del Carmen Cortés Beltrán y María Dolores Cáceres Zapatero titulados “La oferta teatral pública: calidad y apoyo institucional” y “Una aproximación a la diversidad de espectáculos madrileños: tradición, innovación y riesgo", donde hacen un exhaustivo repaso de los diferentes espacios madrileños que existen en este ámbito, según estén vinculados al Instituto Nacional de las Artes Escénicas y Música del Ministerio de Cultura, a la Consejería de Cultura de la Comunidad de Madrid o al Ayuntamiento de Madrid; así como una descripción pormenorizada de los diversos espectáculos que se pueden encontrar en la Comunidad y las principales teatros, teatros alternativos, espacios teatrales, microteatros, así como los espectáculos de 
títeres, representaciones callejeras, la tauromaquia y el cine.

Un recorrido por los lugares dedicados a las artes, fundamental dada la amplia variedad de espectáculo y oferta de entretenimiento existente tanto en toda la Comunidad de Madrid, no solo en la Capital, con una oferta variada que da cobertura a públicos diferentes de todo tipo y que convierte la región en un lugar atractivo para el turismo y la posiciona en una de las principales ciudades europeas en cuanto a ocio.

El capítulo trece trata sobre moda. En "Madrid y la moda", Ángel Fernández Fuente y Patricia Fernández Fuente nos acercan la moda de la región: cuáles son sus principales diseñadores y creadores madrileños; los centros de Formación y las Escuelas; cómo es el Mercado de la Moda de Madrid y dónde están los principales escaparates en Madrid; así como otros factores como los hábitos de consumo y el papel de la prensa y Comunicación en el sector. Nos presentan finalmente un sector no exento de la crisis que encuentra en los Medios de Comunicación su mejor aliado.

El punto final del libro lo pone el capítulo catorce dedicado a "La participación deportiva. Democratización e individualización". Escrito por Ramón Llopis y Juan Jesús Morales Martín, analiza la evolución de la participación deportiva en la Comunidad de Madrid en los últimos años, cómo es la práctica deportiva, el uso y la valoración de las instalaciones y el consumo deportivo y el deporte-espectáculo. Entre las principales conclusiones, está el incremento de la práctica de deporte por parte de la población madrileña durante la primera década del siglo XXI. Un capítulo que supone una aportación fundamental de un aspecto de la realidad social madrileña que se impone de forma integrada y polifacética a la vida de los madrileños.

Con todo, la lectura de este libro complementa el estudio realizado en el primer volumen y enriquece algunos de los aspectos tratados en el anterior, ampliando el conocimiento sobre múltiples aspectos olvidados entonces. A mi parecer, un trabajo mucho más completo, si cabe, que el primero, que ayuda a conocer la realidad social madrileña $\mathrm{y}$, al introducir diversas referencias sobre la historia de Madrid, consigue despertar el interés del lector y le deja con ganas de seguir ampliando el

DOI: ri14.v12i1.686 | ISSN: 1697-8293 | Año 2014 Volumen 12 N 1 | ICONO14 
$506 \mid M^{a}$ del Pilar Gomiz Pascual

conocimiento adquirido. Por su parte, la AMS contribuye con este trabajo, como ya lo hizo con el primer volumen de esta trilogía, en la difusión de conocimiento sociológico de Madrid y lo hace con la calidad y la armonía que ya encontramos en el primer volumen y que, seguramente encontremos en el próximo.

Pilar Gomiz

UNED

pgomiz@poli.uned.es

ICONO14 | 2014 Volumen $12 \mathrm{~N}^{\circ} 1$ | ISSN: 1697-8293 | DOI: ri14.v12i1.686 